EM

\title{
ÑANDE MBARETE! OCUPAÇÕES NO ESPAÇO DE FRONTEIRA
}

\author{
ÑANDE MBARETE! OCCUPATIONS IN THE BORDER SPACE
}

\section{ÑANDE MBARETE! OCUPACIONES EN EL ESPACIO FRONTERIZO}

\author{
Alexandre Bergamin VIEIRA ${ }^{1}$ \\ Kamila Madureira da SILVA ${ }^{2}$ \\ Raphaella Elias PEREIRA ${ }^{3}$ \\ Lucas Manoel Cardoso de OLIVEIRA ${ }^{4}$
}

\begin{abstract}
Resumo: Este artigo trata da análise acerca dos processos sociais, econômicos e culturais que englobam as complexas relações fronteiriças, percebidas a partir do trabalho de campo na tríplice fronteira Brasil-Paraguai-Argentina. Compõem esta análise o acampamento "Linha Oito" (Brasil), o território Maká (Paraguai) e Tekoha Iryapú (Argentina), contemplando suas especificidades e relações oriundas da mobilidade e complexidade presentes na fronteira, temas de importância relevante na discussão tais como: luta pela moradia, direito do lugar como território, a mulher como chefe de família, cultura e identidade, todo este processo permeado por uma constante luta pela dignidade de um povo. Todas estas questões vistas pela ótica do sistema capitalista de produção, que por sua vez é repleto de agruras e preconceitos e extremamente excludente que, como as linhas de um trançado formam um tecido, as características deste sistema se cruzam, e refletem nas situações que propomos refletir. As transformações no território desaguam num constante processo de desterritorialização e reterritorialização, tratando-se tanto do "chão", do espaço, mas também do indivíduo que constrói a sua identidade em meio a tais transformações, ao mesmo tempo que luta pelas suas convicções, sobrevivência, dignidade e, principalmente, pela manutenção de sua cultura, lugar e valores que são imensuráveis e invendáveis.
\end{abstract}

Palavras-Chave: Fronteira; Território; Identidade; Luta.

Abstract: This article deals with the analysis of the social, economic and cultural processes that encompass the complex border relations, perceived from the fieldwork on the triple Brazil-ParaguayArgentina border. This analysis comprises the camp "Linha Oito" (Brazil), the territory Maká (Paraguay) and Tekoha Iryapú (Argentina), contemplating their specificities and relationships arising from the mobility and complexity present on the border, topics of relevant importance in the discussion such as: struggle for housing, the right of place as a territory, women as the head of the family, culture and identity, this whole process permeated by a constant struggle for the dignity of a people. All these issues seen from the perspective of the capitalist system of production, which in turn is full of hardships and prejudices and extremely excluding that, as the lines of a braid form a fabric, the characteristics of this system intersect, and reflect in the situations we propose reflect. The transformations in the territory result in a constant process of deterritorialization and reterritorialization, dealing both with the "floor", with space, but also with the individual who builds his identity in the midst of such transformations, while fighting for his convictions, survival, dignity and, mainly, for the maintenance of its culture, place and values that are immeasurable and unsaleable.

\footnotetext{
${ }^{1}$ Doutor em Geografia. Professor dos Cursos de Graduação e Pós-graduação em Geografia da UFGD. E-mail: alexandrevieira@ufgd.edu.br. Membro do Grupo de Pesquisa GESF (Grupo de Pesquisa Saúde, Espaço e Fronteira(s)) e coordenador do LAPLAN/UFGD.

${ }^{2}$ Licenciada em Geografia. Discente do Mestrado em Geografia da UFGD. E-mail: kamila_agro@ hotmail.com.

${ }^{3}$ Licenciada em Geografia. Especialista em Educação do Campo. Discente do Mestrado em Geografia da UFGD. E-mail: raphaella.elias@hotmail.com

${ }^{4}$ Bacharel em Gestão Ambiental. Discente do Mestrado em Geografia da UFGD. E-mail lc123_4@ hotmail.com
} 
EM

Keywords: Frontier; Territory; Identity; Struggle.

Resumen: Este artículo aborda el análisis de los procesos sociales, económicos y culturales que engloban las complejas relaciones fronterizas, percibidas desde el trabajo de campo en la triple frontera Brasil-Paraguay-Argentina. Este análisis comprende el campamento "Linha Oito" (Brasil), el territorio Maká (Paraguay) y Tekoha Iryapú (Argentina), contemplando sus especificidades y relaciones derivadas de la movilidad y complejidad presentes en la frontera, temas de relevancia en la discusión como: lucha por la vivienda, el derecho al lugar como territorio, la mujer como cabeza de familia, la cultura y la identidad, todo este proceso permeado por una lucha constante por la dignidad de un pueblo. Todos estos temas vistos desde la perspectiva del sistema capitalista de producción, que a su vez está lleno de penurias y prejuicios y extremadamente excluyente que, como las líneas de una trenza forman un tejido, las características de este sistema se entrecruzan, y se reflejan en las situaciones que proponemos. reflejar. Las transformaciones en el territorio resultan en un proceso constante de desterritorialización y reterritorialización, atendiendo tanto al "suelo", al espacio, como al individuo que construye su identidad en medio de tales transformaciones, mientras lucha por sus convicciones, supervivencia, dignidad y, principalmente, por el mantenimiento de su cultura, lugar y valores que son inconmensurables e invencibles.

Palabras Clave: Frontera; Territorio; Identidad; Lucha.

\section{Introdução}

Neste artigo, ousamos ilustrar as mais íntimas indagações acerca dos processos sociais, econômicos e culturais que englobam as complexas relações fronteiriças, permeadas de mobilidade e conflitos e, assim, tentar traduzir em palavras as inquietudes e sensações que experienciamos na realização de trabalho de campo na tríplice fronteira Brasil-ParaguaiArgentina.

No presente artigo tratamos de tecer uma colcha de retalhos, costuras de emaranhados entre a experiência de conhecer e desvendar as características e especificidades do Acampamento "Linha Oito" (Brasil), dos povos Maká (Paraguai) e Tekoa Iryapú (Argentina) localizados junto à Linha Internacional entre o Brasil, o Paraguai e a Argentina e as relações oriundas da mobilidade e complexidade presentes na fronteira.

Abordaremos temas como busca pela moradia, direito do lugar como território, a mulher como chefe de família, cultura e identidade. A luta cotidiana pela dignidade de um povo, transformações do espaço como um sempre porvir, a problemática social inserida em cada discussão, em cada diálogo e em cada olhar, de povos distintos ocupando um mesmo território, de dominação e poder, de afeto e cultura. 
EM

QUESTÃO

V.13 N. $04 \bullet 2020$

pág. 111-132

\section{O acampamento, luta pela moradia e a fronteira}

Mesmo localizado distante do perímetro urbano de Mundo Novo a primeira impressão insta perceber que o movimento de ocupação trata-se da luta pela moradia, não relacionada à luta pela terra relacionada à agricultura ou a reforma agrária, devido ao tamanho dos lotes e à disposição dos mesmos e seu arruamento, no formato de loteamento urbano (figura 1).

Figura 1 - Localização do Assentamento "Linha Oito".

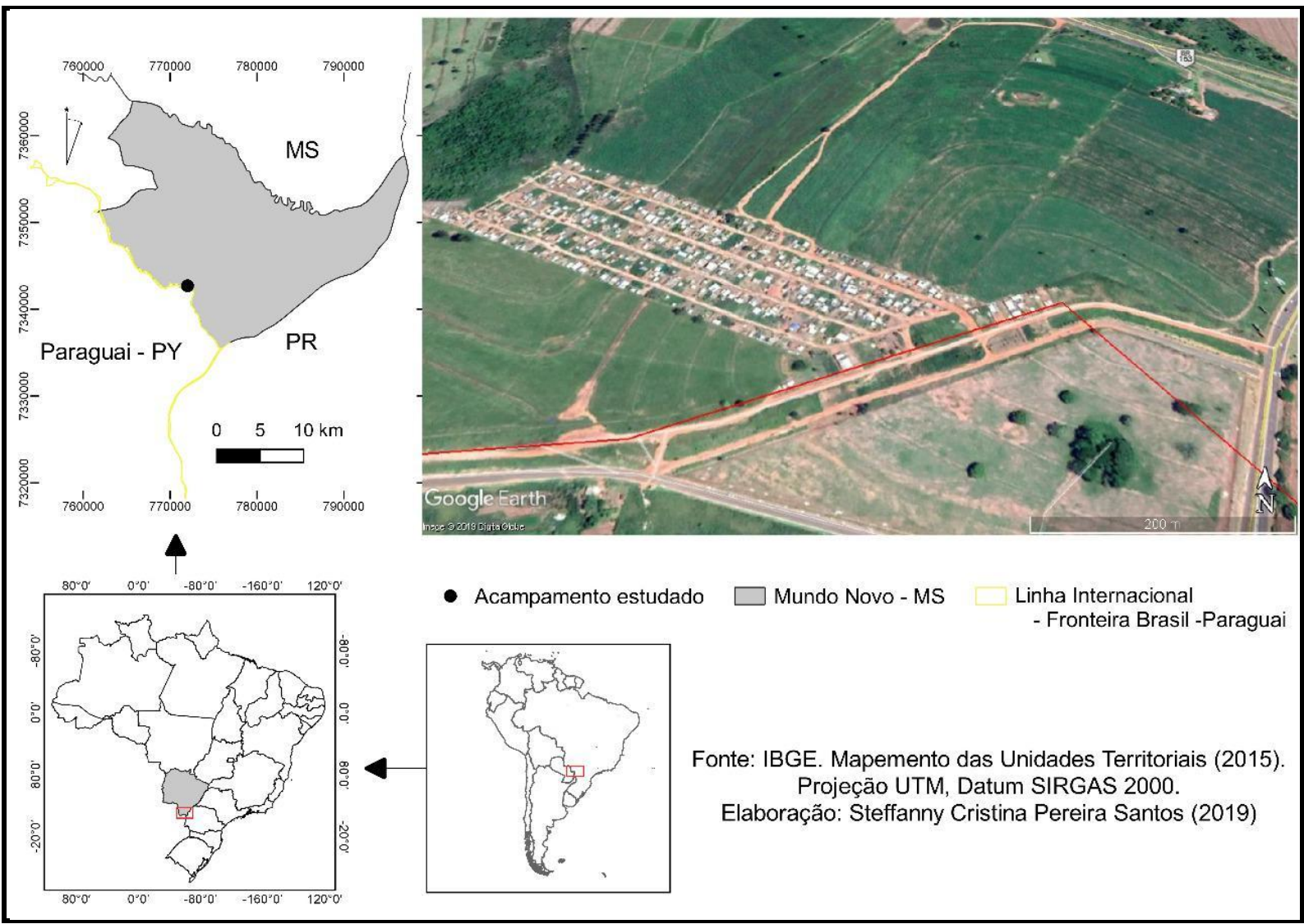

Fonte: Elaboração de Steffany Cristina Pereira Santos.

Desenvolvimentos geográficos desiguais mascaram a verdadeira natureza do capital, visto que indivíduos e grupos tentam moldar espaços e lugares para si próprios, orientados pela regra da acumulação do capital e pelo poder do Estado. O capital acaba por ser "sensível" às necessidades da população a qual ele explora, pois caso não fosse seria forçado a tornar-se, pela pressão exercida pelas lutas sociais e de classes (HARVEY, 2016).

Segundo Harvey (2005), as lutas comunitárias, as alianças de classes são presentes em aspectos regionais e locais, e mesmo que as mesmas já não fossem presentes, os processos em andamento dentro do capitalismo as criariam: 
$\mathrm{Na}$ medida em que nas últimas décadas, as políticas neoliberais desmantelaram grande parte das proteções criadas com tanto esmero durante décadas de luta, estamos cada vez mais expostos a alguns dos piores aspectos desse "moinho satânico" que o capital, por si só, inevitavelmente cria. (HARVEY, 2016, p. 62)

Apontamos, ainda, a questão da feminização da pobreza. Conforme Arriagada (2002), o aumento da pobreza associado ao processo de deterioração econômica, o crescimento de empregos sem vínculos ou vínculos instáveis ou informais e do desemprego além de afetar a população mais pobre, afeta principalmente mulheres.

Outra transformação refere-se à estrutura familiar, o aumento dos lares em que as mulheres são chefes de família, mesmo havendo a presença do homem há a observância da dependência da renda da mulher, fato repetidamente constatado no Acampamento "Linha Oito", no qual os lares onde realizamos as entrevistas eram, na sua quase totalidade, geridos e estavam sob responsabilidade das mulheres.

Outra questão característica do capitalismo e observada em "Linha Oito" é o desenraizamento, possuindo a tendência de destruir as relações sociais que não sejam puramente capitalistas, transformando as pessoas em apenas possuidoras de força de trabalho, e potenciais vendedoras delas, fazendo com que estejam sempre em busca de meios de sobrevivência e, para tal, são obrigadas muitas vezes a sair de um lugar para o outro, o que envolve outro problema social a dificuldade de inclusão, seja na economia, nas relações sociais, na cultura, sendo então submetidos a privações não apenas materiais, ou seja, a exclusão social também é subjetiva e de relações sociais (VIEIRA, 2009).

De acordo com Martins (2003) as migrações internas estão em grande parte apoiadas nos mesmos fatores das imigrações internacionais: desemprego ou subemprego, busca pela moradia, diferentemente das migrações internas que ocorriam no passado, que eram parte fundamental de ascensão social, elevação a um padrão de vida moderno e emancipador. Isso é nitidamente percebido em "Linha Oito", onde os moradores, em sua grande maioria, desenvolvem alguma atividade predominantemente informal em Salto Del Guaíra e uma minoria em Mundo Novo, visto que a localidade paraguaia trata-se de um município maior.

Podemos então entender através de Martins (2003) que são (i)migrações que desagregam sem transformar, pois, os (i)migrantes acabam por aceitar condições degradantes de trabalho e, más condições de vida, dignidade e direitos e, infelizmente, também do sentido de pertencimento. O próprio ato de migrar já contextualiza a perda, expulsão, antes migrava- 
EM

QUESTÃO

V.13 N. $04 \bullet 2020$

pág. 111-132

se para "subir na vida" hoje migra-se para "evitar a queda", o desesperado esforço de estabelecer algum ordenamento social.

Fatos e realidades nitidamente observados no Acampamento "Linha Oito", (i)migrantes em sua maioria, excluídos e sem teto, que se revelam numa complexidade de ir e vir (figura 2) ou permanecer. E que hoje encontram-se inseridos em território fronteiriço, que pode ser entendido como um conjunto de "itinerários e lugares" (HOLZER, 1997, p. 83). Na realidade estudada, a existência do território não reclama a delimitação de fronteiras fixas, e sim flexíveis, visto que os limites são dados de acordo com as relações (espontâneas ou não, conflituosas ou não) frente (ou junto) a outros grupos, com a necessária alteridade.

Figura 2 - Ir e vir (ou permanecer?) no Acampamento "Linha Oito".

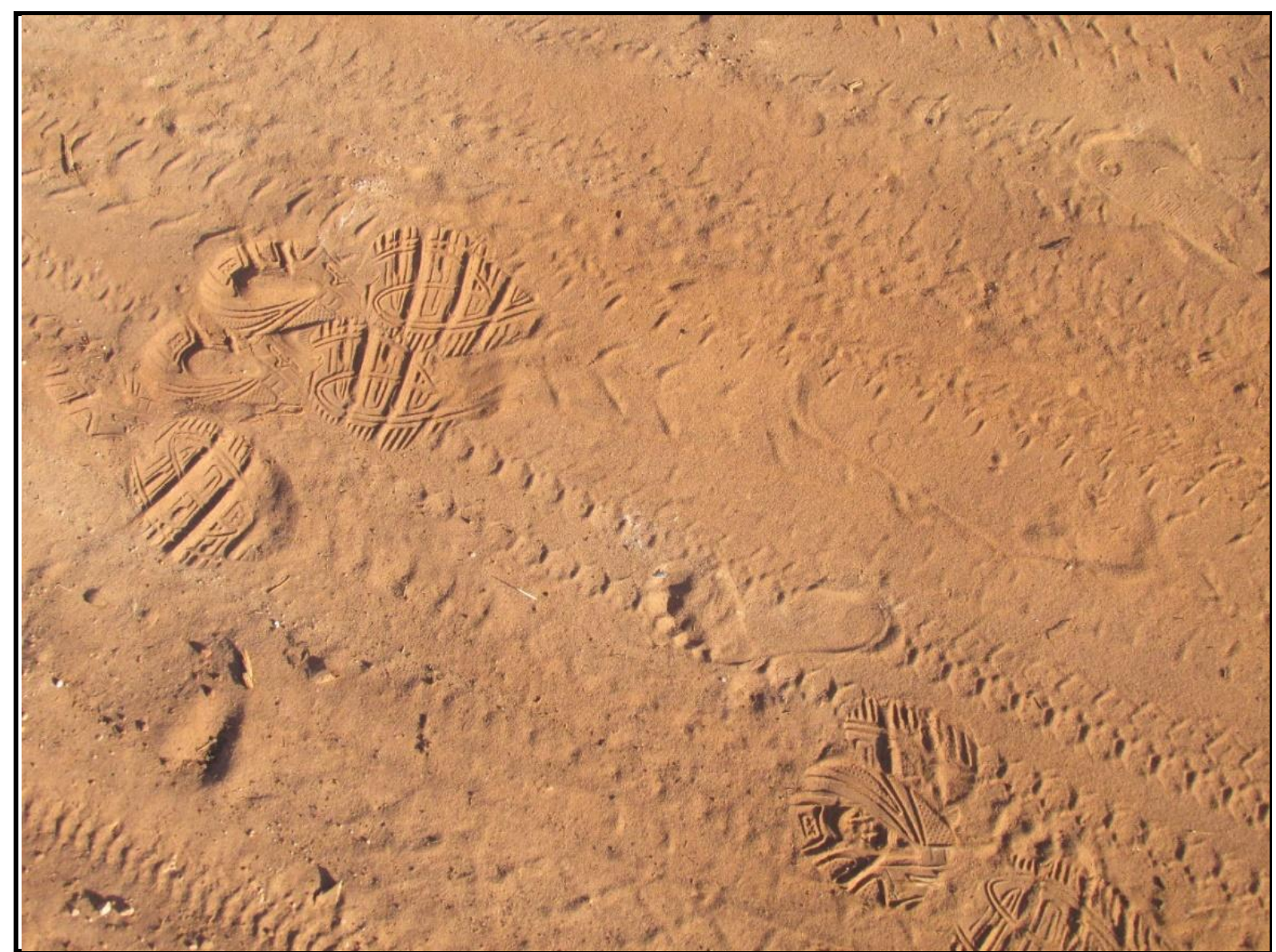

Fonte: SILVA, K.M. (2019). Trabalho de Campo.

\section{Na complexidade da fronteira - um acampamento}

Conforme Albuquerque (2010) na atualidade a palavra fronteira adquire aspectos tanto territoriais, geográficos quanto metafóricos, para demarcar ou apagar limites culturais, sendo 
EM

QUESTÃO

V.13 N. $04 \bullet 2020$

pág. 111-132

muitas vezes confundido com limite e divisa. A fronteira é vista como zona entre dois países, é um espaço mais amplo de relações sociais de um lado e outro do limite politico. O limite internacional é delimitado linha de fronteira, sendo abstrato e invisível, fruto de um tratado jurídico internacional ou delimitação.

A fronteira, comumente, também indica um limite (figura 3), ela aponta onde tem início ou fim de um determinado território, cujo limite estabelece a soberania nacional e serve para assinalar o que pertence a ele, quais as suas competências e os elementos que dele fazem parte e o que pertence ao outro. Mas, ela não se resume às suas delimitações geográficas. A demarcação normatizada de uma linha ou faixa divisória de natureza política entre duas partes estimula a ocorrência de práticas de afirmação, adaptação e tensão. Ao mesmo tempo, em que constitui um cenário de intolerância, ambição e morte é também lugar da esperança, de justiça, de alegria e de vida.

Figura 3 - Limite do acampamento e a linha de fronteira Brasil-Paraguai.

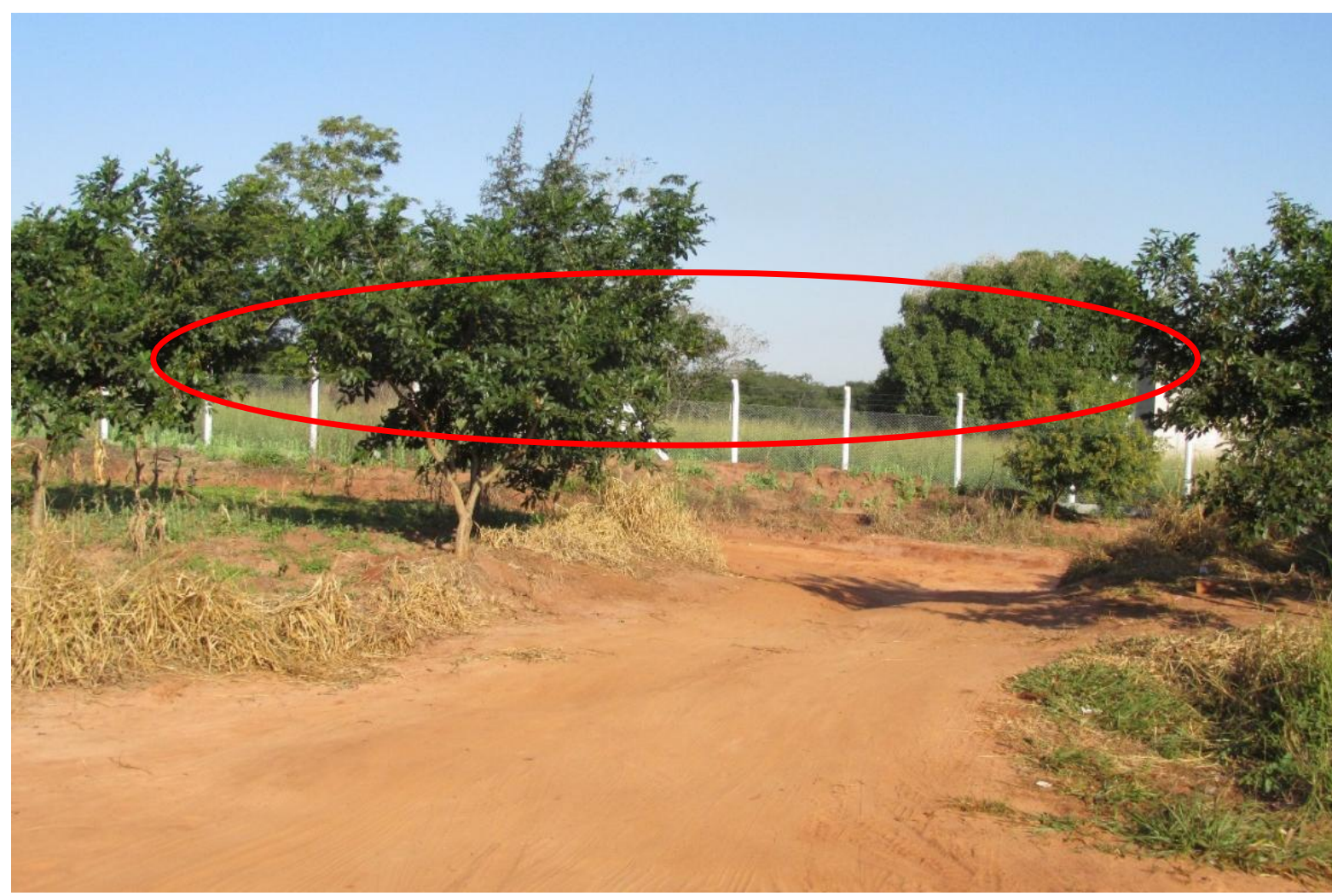

Fonte: SILVA, K.M. (2019). Trabalho de Campo.

A divisa representa a visibilidade limítrofe na paisagem geográfica deste limite invisível, sendo percebido pelos marcos visíveis e controles alfandegários e, no caso do acampamento "Linha Oito", um alambrado erguido pelo capital. 
EM

O imaginário popular é sempre povoado e bombardeado por estigmas referentes aos espaços de fronteira. Para conhecer e perceber a complexidade da fronteira é necessário vê-la sob diversos ângulos. A visão daqueles que vivem próximo é muito diferente daqueles que vivem longe. Para aqueles que vivem a e/ou na fronteira, esta faz parte do cotidiano, é fonte de trabalho formal e/ou informal, do contrabando, do tráfico e "muambas", do turismo, da riqueza e da pobreza, da inclusão e da exclusão social, ou seja, para além de espaço da norma ela se constitui como território usado (SANTOS, 1999), onde as inter-relações culturais, econômicas, sociais e políticas assumem uma determinada frequência e intensidade que se misturam num espaço onde de fato a fronteira parece inexistir, onde "tudo" é possível, desde o transitar, até o engajar-se no mercado de trabalho, passando a usufruir e a transmitir os elementos do que está do lado de cá e do lado de lá, que normativamente se instaura, mas que na prática se esvai.

É exatamente esta complexidade e este conflito que observamos nas entrevistas no Acampamento "Linha Oito". Notamos que mesmo residindo em um mesmo território e compartilhando a mesma luta, pela terra, pela moradia, ou seja, a motivação sendo a mesma, os indivíduos se diferenciam entre si, formando grupos, em que há a divergência de ideias, e até mesmo sendo perceptível, talvez não claramente, mas nas entrelinhas dos diálogos no decorrer das entrevistas, um certo ar de rivalidade, e até mesmo de superioridade de um grupo para com o outro, ou até mesmo um preconceito velado dos brasileiros para com os imigrantes paraguaios, havendo casos, em que através da oralidade há a percepção de seus laços com o país vizinho, o indivíduo não se identifica como paraguaio, ou descendente dos mesmos.

Em conversas com moradores, percebemos uma divisão, em que os lotes da parte superior, mais próximo à linha da fronteira, pertencem aos brasileiros, já os lotes mais abaixo pertencem aos paraguaios ou brasiguaios, sendo notável a situação de maior vulnerabilidade dos paraguaios em relação aos brasileiros, sendo apontados pelos brasileiros como "preguiçosos", mesmo que de forma velada, e por esta razão vivem em situação de maior vulnerabilidade.

O problema é saber como e por que os indivíduos percebem uns aos outros como pertencentes a um mesmo grupo e se incluem mutuamente dentro das fronteiras grupais que estabelecem ao dizer "nós", enquanto, ao mesmo tempo, excluem outros seres humanos a quem percebem como pertencentes a outro grupo e a quem se referem coletivamente como "eles" (ELIAS, 2000, p.38). 
Tal fato pode estar relacionado com o que explicitam Poutignat e Fenart (2011) quando discutem Connor (1978/1993): a questão da nação e o fortalecimento da nacionalidade advêm do fato das pessoas acreditarem que estão ligadas por uma filiação ancestral, manifestando a solidariedade étnica e/ou nacionalista quando em confronto com elementos estrangeiros e origina-se na xenofobia, ou seja, a convicção que seus membros formam um mesmo povo, devido à origem comum e um mesmo sangue. E isso e nítido no acampamento "Linha Oito" e reforçado pela sua posição fronteiriça.

Conforme Bauman (2005), estar totalmente "deslocado" em toda parte, não estar totalmente em lugar algum, ou seja, ser considerado estranho em algum aspecto pode ser uma experiência desconfortável, até conseguir sentir-se "em casa", paga-se um alto preço para a aceitação de sua identidade, que é oriunda de um processo de construção, e não de descoberta, e este processo é uma luta, como também é uma luta o exercício constante de protegê-la.

Assim como na figura 4, abaixo, o homem dentro do sujeito que (e)migra, se esfacela, se rompe e posteriormente volta a se reconstruir, ou a se construir enquanto um novo individuo, devido as relações que constrói ao longo do processo de migração.

Figura 4 - A (re)(des)construção na fronteira.

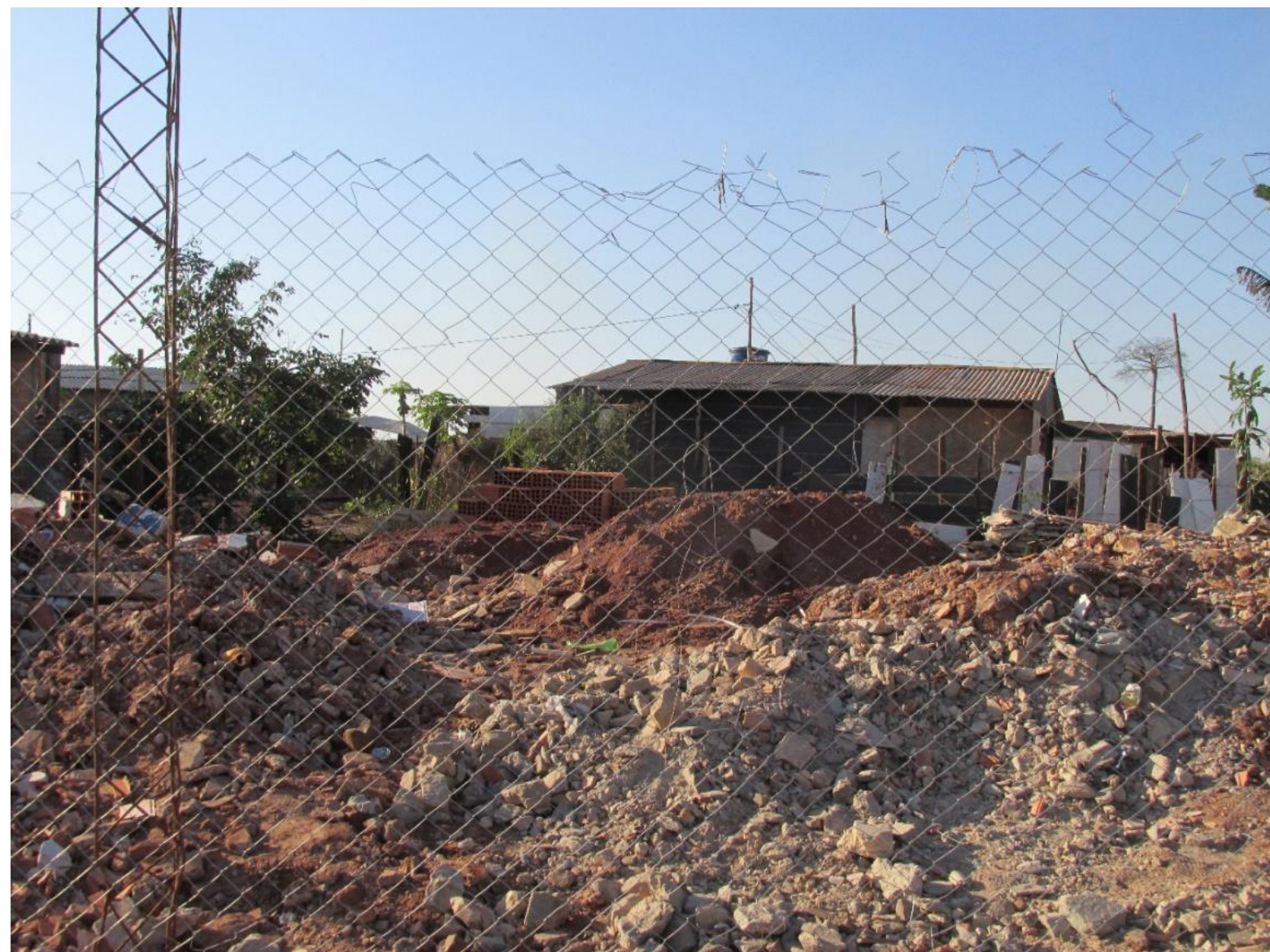

Fonte: SILVA, K.M. (2019). Trabalho de Campo. 
EM

No processo de mobilidade o individuo não é mais o mesmo, muito se perde pelo caminho e muito é absorvido também, há o processo de reconstrução ou construção de uma nova identidade, que pode ser fruto da assimilação da cultura do outro, ou até mesmo da luta pela manutenção de sua própria, mas sem dúvida há a construção de um mosaico oriundo dos processos e relações ao longo das vivencias.

Dentre os processos relacionados ao território, nos deparamos com as territorialidades, que são culturais, políticas e econômicas, estas que são construídas ao longo da existência do individuo e perceptíveis no acampamento.

No processo de mobilidade acaba havendo a desterritorialização dos indivíduos e automaticamente a sua re-territorialização, como abordam Deleuze e Guatarri apud Saquet (2015) a reconstituição, restituição do poder. O capitalismo tece a re-territorialização a partir da desterritorialização, obtemos então o conceito de T-D-R trabalhado posteriormente por Raffestin (1984).

Se a territorialização é, sobretudo, enraizadora, promovendo a coesão por seu caráter mais intrínseco e introvertido, é claro que ela vai estar ligada muito mais às iniciativas político-culturais de apropriação e domínio do que à dinâmica do capital, cujo caráter é intrinsecamente desterritorializador e "sem pátria". (HAESBAERT, 1995, p.178).

Nos diálogos com os moradores percebemos que a composição do acampamento consiste em brasileiros oriundos de diversas partes do país, além de paraguaios, percebidos através da oralidade, pois os entrevistados não se identificam como tal. Esta mobilidade remete aos conceitos de T-D-R, pois no ato de deixar sua origem, ficam para trás as relações sociais, de trabalho e culturais, para ingressar uma nova construção, até mesmo de identidade, processo este complexo, pois além de todos os fatores inerentes ao social e cultural, há a dificuldade da manutenção das necessidades básicas de sobrevivência, como acesso a água, energia elétrica, alimentação, documentação, acesso ao perímetro urbano nos dois lados da linha.

O acampamento possui hoje cerca de 60 famílias paraguaias, e grande parte deles não possui documentação brasileira, o que dificulta acesso aos serviços sociais: algumas famílias brasileiras entrevistadas têm no Programa Bolsa Família única fonte de renda; em outra casa a única fonte de renda é o BPC de um membro deficiente, há ainda pescadoras profissionais que recebem o beneficio na época da piracema. Enfim, em nenhuma das entrevistas nos deparamos com trabalhadores desenvolvendo trabalhos formais, o que dificulta o processo de inserção social e econômico, e consequentemente a territorialização. 
EM

QUESTÃO

V.13 N. $04 \bullet 2020$

pág. 111-132

\section{A arte indígena na fronteira capitalista}

A tríplice fronteira entre Brasil, Paraguai e Argentina guarda muitas surpresas para quem busca vislumbrar seu potencial e sua diversidade. Povos de várias raças, cores gêneros e etnias, habitam esse território que compõem uma imensa multiplicidade fazendo com que o mesmo não seja uma fronteira inerte, e que nela ocorram fenômenos e movimentos diversos que a torna única e ao mesmo tempo múltipla.

As regiões de fronteira internacional na atualidade têm se convertido em espaços de múltiplos significados, complexos de coexistências, conflitos e permanente processo de transformação de suas relações socioespaciais (CAMPOS, 2015).

As fronteiras nacionais são fenômenos bem mais complexos, não se resumem a limites, divisas, tratados diplomáticos, nem podem ser simplificados como o lugar do narcotráfico e do contrabando. Não existe a fronteira em abstrato, o que existem são situações sociais e singulares de fronteiras. Alguns fenômenos podem ser generalizados para outros contextos fronteiriços e outros são específicos de uma dada configuração social. (ALBUQUERQUE, 2010, p. 42).

Toda essa diversidade e multiplicidade geram o agrupamento de várias e diversas culturas que juntas compões o que o podemos caracterizar como fronteira diversa e única, onde o fluxo e os componentes sociais são imersos na modernidade desenfreada do capitalismo.

Toda essa intensidade social sinaliza uma realidade cultural singular, fomentada por fluxos migratórios que não cessam de adensar, povoar e movimentar a região. [...]Esses deslocamentos e seus povoamentos acabam por gerar relações provocadoras de desigualdades sociais, de tensões interculturais, de encontros e desencontros. Encontros, porque a região, por sua densidade social, também guarda uma riqueza cultural, brechas do convívio, da sociabilidade que se abrem para além dos motivos econômicos e por vezes alçam relações sociais amistosa. (NOGUEIRA E CLEMENTE, 2011, p.3).

Segundo Ferrari (2013, p.88), as interações que são realizadas nas fronteiras não se encontram apenas no viés econômico, conjuntamente com esse viés, temos todo um conjunto de interações (materiais e imateriais), onde estão contidas também as culturais, pois para que haja essas interações, se faz necessária a atuação do sujeito fronteiriço, que compõe múltiplas identidades, e que através dessa relação consegue conceber as zonas fronteiriças. Podendo criar assim fronteiras com múltiplas culturas que habitam um mesmo território, geradas 
principalmente pela constante migração de povos para um determinado território, o que consegue gerar a multiplicidade de culturas e povos.

Na tríplice fronteira há vários e diversos casos (e)migração de povos (conjuntamente com suas culturas), visando a sobrevivência de parte de seu povo.

O povo Maká, presente no centro comercial de Ciudad del Este, é um povo indígena oriundo da região do Chaco Paraguaio, que a partir de 1944 dividiu-se em várias regiões do pais, e que atualmente se encontram em quatro assentamentos de fronteira do Brasil com o Paraguai, na fronteira da Argentina com o Paraguai, e principalmente na cidade de Assunção, capital do Paraguai (BENITEZ, 2016).

Encurralada no centro de consumo capitalista de Ciudad del Este (figura 5), a comunidade Maká, busca sua sobrevivência através da produção e comercialização de artesanatos que representa uma importante fonte de renda para a comunidade, e também pela arrecadação de donativos. Toda a comunidade Maká vive em um espaço bastante simples e precário, transformando-os em mais alguns indivíduos em meio à multidão.

Adentrar o território comercial de Ciudad del Este, na tentativa de encontrar a comunidade não é tarefa fácil para quem embarca em uma primeira viagem nesse intuito. Mas com algumas ajudas e um pouquinho de fluência em "portunhol" conseguimos localizar a comunidade. Depois de um sobe e desce cansativo de algumas ladeiras, encontramos a tão escondida (ou negligenciada) comunidade.

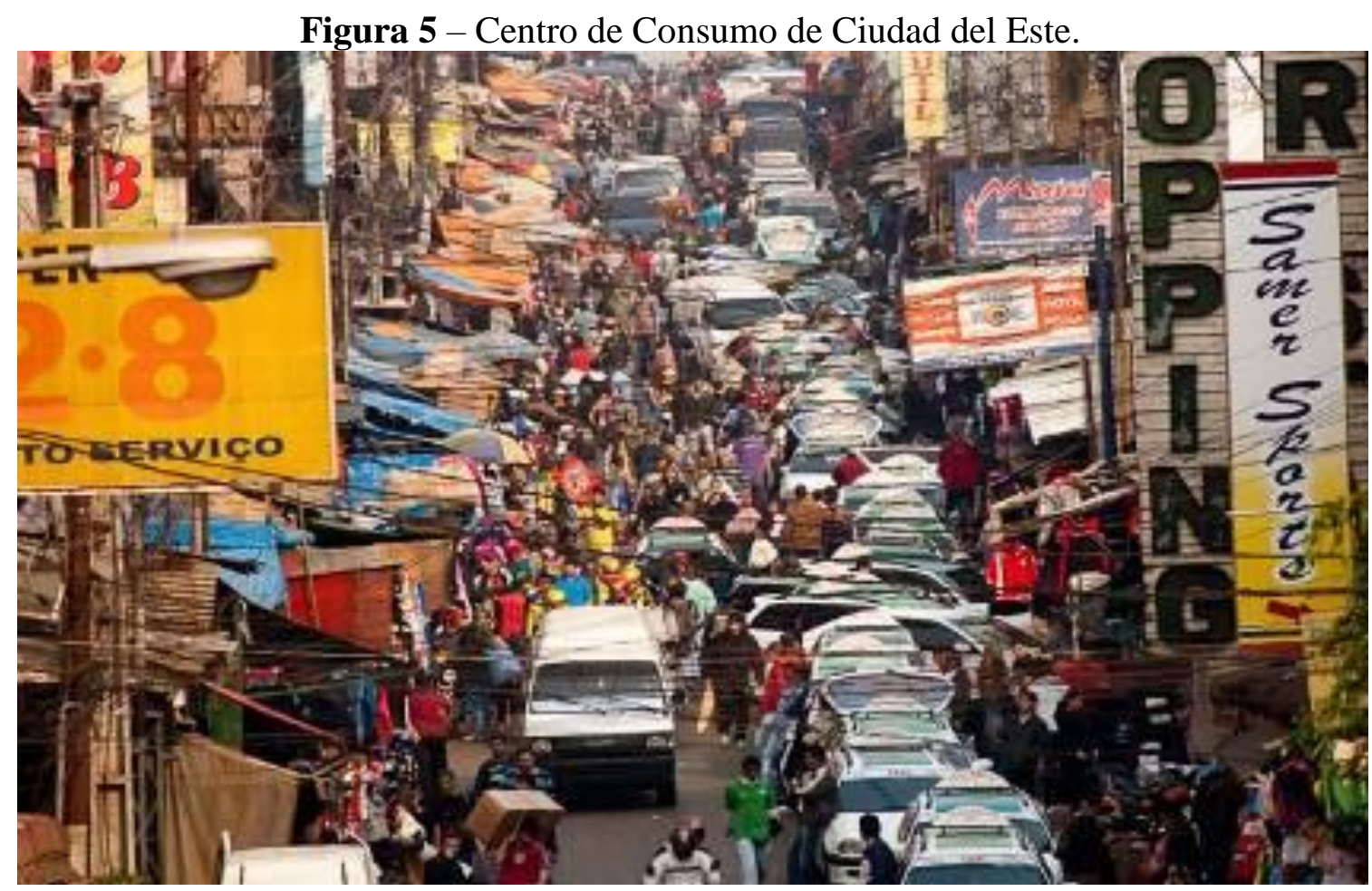

Fonte: PEREIRA, R.E. (2019). Trabalho de Campo. 
O acesso é permitido apenas com autorização do Cacique, que apresenta com orgulho seu povo e cultura, que não desistirá do seu lugar, mesmo com o fluxo constante de veículos, vendedores, turistas e tudo mais que o capitalismo comercial propõe. Os Makás sobrevivem principalmente, da venda de suas artesanias.

A primeira vista mostra-se imponente com uma fachada toda entalhada com arte indígena, contudo, ao adentrar a comunidade, vislumbramos outra realidade (figura 6). Esse povo vive em uma comunidade que mais lembra um cortiço, com suas vielas e corredores apertados e suas casas confeccionadas primordialmente de madeira, uma colada na outra, onde vivem cerca de 40 famílias que, juntas, buscam incansavelmente manterem vivas a suas tradições e cultura, mesmo com todas as influências trazidas pela fronteira e pelo capitalismo.

Figura 6 - Fachada da comunidade Maká em Ciudad del Este.

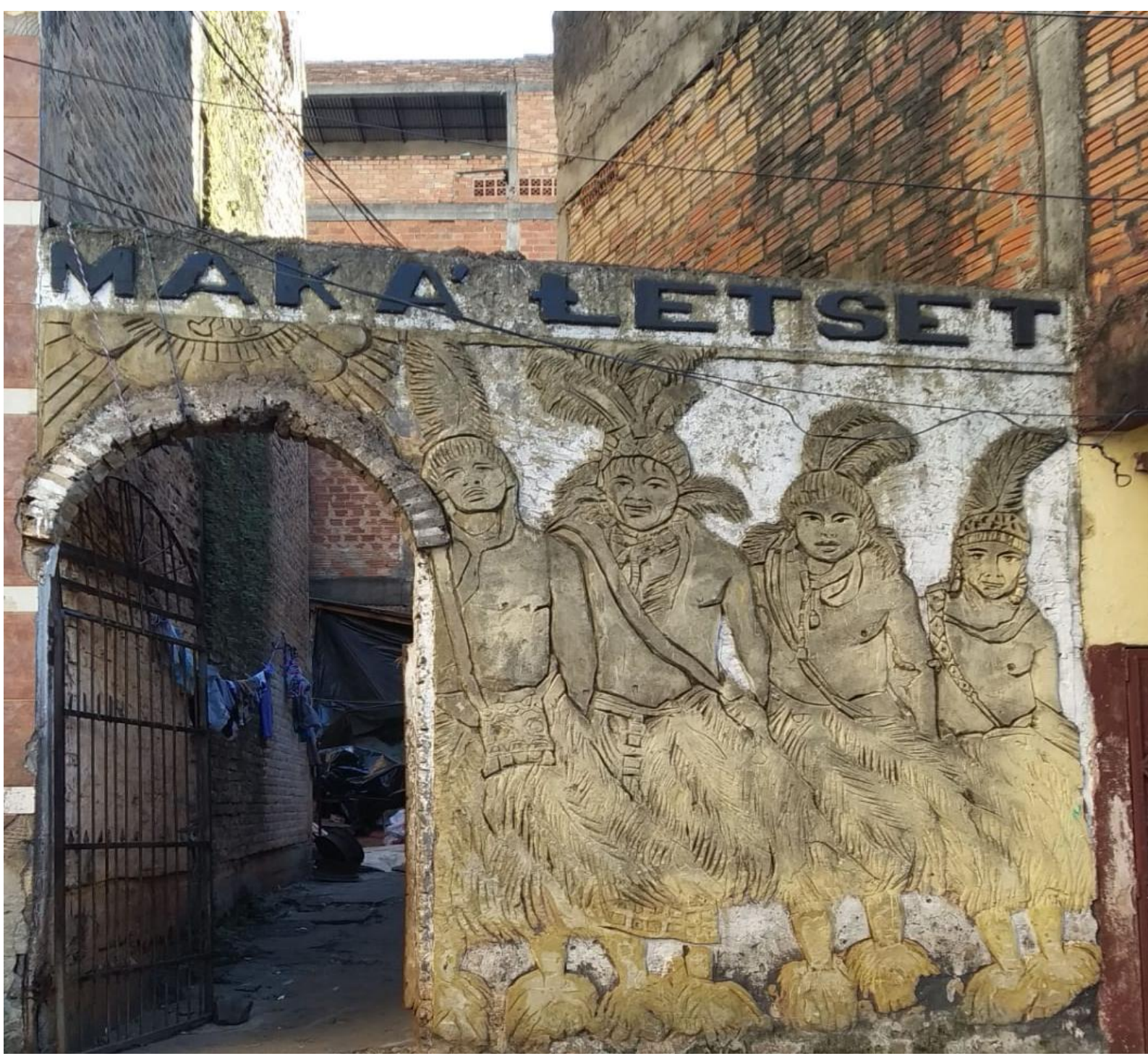

Fonte: PEREIRA. R. E. (2019). Trabalho de Campo. 
EM

QUESTÃO

V.13 N. $04 \bullet 2020$

pág. 111-132

A comunidade se localiza em um terreno e uma estrutura principal cedidos pela prefeitura, onde alfabetizam suas crianças e adolescentes primordialmente na língua nativa de seu povo. Eles também participam de programas sociais da prefeitura, ao qual recebem auxílio financeiro e de saúde, mas ainda veem bastante dificuldade em auxílios para a alimentação e vestimentas. Têm como o principal intuito a continuidade e a valorização de sua cultura pela alfabetização na linguagem tradicional como primeiro idioma, mas que compreendem a necessidade de preparação das futuras gerações para o sistema capitalista, incentivando-os a aprender o idioma do território para conseguir escrever o seu próprio futuro. Assim desde muito novo o indivíduo da comunidade já é levado a entrar em contato com as múltiplas interações geradas pela fronteira, ao que ele terá que enfrentar para manter viva as suas esperanças e a sua cultura.

Praticamente ignorados em meio à agitação do centro comercial da cidade, a comunidade vive literalmente as margens da sociedade, buscando notoriedade em meio ao caos que acaba se tornando diariamente naquele território. Todos os dias os incansáveis indivíduos pertencentes a comunidade se inserem em meio à confusão diária do centro comercial, com o principal intuito de comercializar seus produtos e arrecadar recursos para garantir a sobrevivência de sua família e de sua cultura.

A fronteira nesse caso é uma das protagonistas nessa história, pois é em principal, por causa de sua multiplicidade e sua diversidade, que as pessoas são atraídas a querem visitar, conhecer, desbravar esse território.

Assim, ao mesmo tempo em que a fronteira é limite, pois foi desta forma instituída geopoliticamente, também é acesso, já que pode ser transposta em ocasiões e por motivos específicos. As relações de consumo são aspectos motivadores da condição transfronteiriça. Para desempenhar os atos de comércio e consumo, algumas pessoas migram cotidianamente ao "outro lado" da fronteira. (POLON, 2015 p.72)

E é assim, também através da fronteira que o povo Maká busca seu sustento. Da mesma forma que podemos encontrar a comercialização dos produtos de artesanatos dos Maká dentro dos centros comerciais do Paraguai, conseguimos encontra-los atravessando as fronteiras, próximo aos pontos turísticos e locais de grande circulação dentro do Brasil e da Argentina. A fronteira torna-se assim um elo para garantir a manutenção e sobrevivência do povo e de sua cultura, e auxilia na disseminação dos traços da herança sociocultural de seus ancestrais, contribuindo para o conhecimento e a miscigenação das culturas. 
Com uma rica cultura o povo Maká, desenvolve principalmente seu artesanato (figura 7) com a produção de bolsas, correntes, pulseira, colares de tecido e a produção de arco e flecha. As bolsas mais elaboradas e maiores, são confeccionadas pelas anciãs artesãs do povo, que residem principalmente na capital do Paraguai. A matéria prima para produção dessas bolsas diferente de outras culturas indígenas, na cultura Maká são provenientes de centro comerciais de tecidos e não diretamente da natureza, demonstrando assim a constante inserção dos povos indígenas nos processos de globalização e industrialização. Essas bolsas depois de confeccionadas são enviadas para as ramificações da comunidade de fronteira para a comercialização. Já os colares e pulseiras conseguem ser desenvolvidas nas comunidades, e são desenvolvidas principalmente pelas mulheres e jovens da comunidade, que desde muito pequenas as meninas já começam a ter contato a arte de confecção passadas de geração para geração. Essas pulseiras são confeccionadas independentemente por cada família e o valor arrecadado com a venda recaem para a família que produz e comercializa o artesanato.

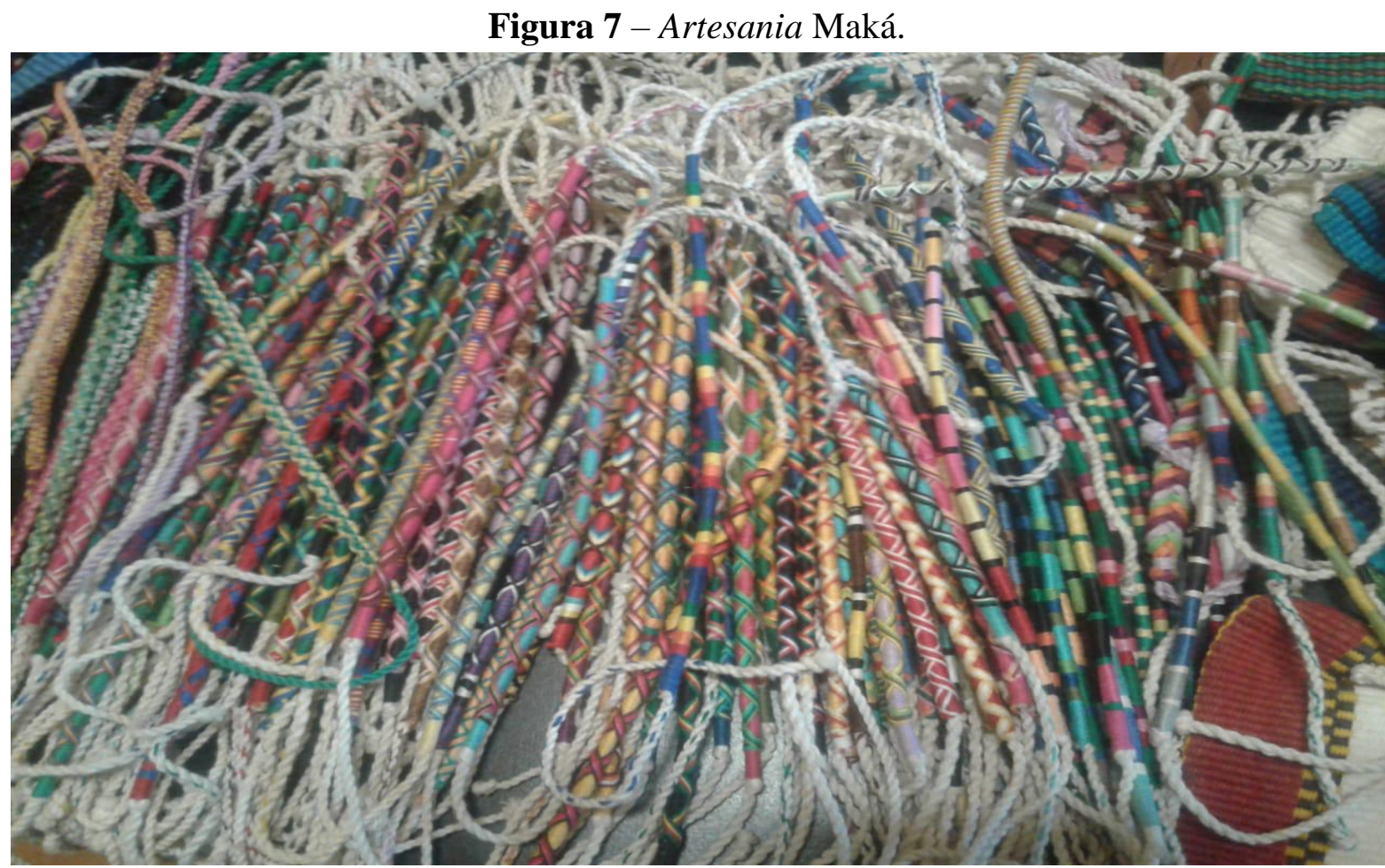

Fonte: PEREIRA, R.E. (2019). Trabalho de Campo.

A confecção de arco e flecha fica sob a responsabilidade dos homens, que desde muito jovens aprendem a arte de confecção desse objeto. Forjado principalmente através do Timbó, uma madeira típica de região de origem da comunidade. Timbó que segundo a Carvalho (2002), são arvores de ocorrência no Paraguai, de médio porte e que também é utilizada de diversas formas na região. $\mathrm{O}$ arco e flecha fica a cargo dos homens da comunidade pois, 
EM

originalmente, são com essas ferramentas que realizavam a caça e pesca em busca do sustento de suas famílias. Utilizam assim de uma ferramenta de seu povo, componente da cultura ancestral, para comercializar e assim também obter renda para a comunidade.

Ao realizarmos uma busca na Internet, sob os termos "Maká", "povos indígenas "Maká", ou qualquer outro termo relacionado a essa comunidade indígena específica, encontramos apenas um único trabalho ${ }^{5}$ sobre este povo. Um povo com uma carga cultural imensa e que contribui para a diversidade cultural da fronteira, é um povo rico culturalmente, mais tão negligenciado socialmente. Representam nos pontos turísticos da fronteira e nos eventos oficiais e folclóricos uma fantasia e como representantes da população indígena do Paraguai, conforme aponta Benitez (2016).

Nesse sentido,

É inegável que a cultura se transformou em algum gênero de mercadoria. No entanto, também há a crença muito difundida de que algo muito especial envolve os produtos e os eventos culturais (estejam eles nas artes plásticas, no teatro, na musica, no cinema, na arquitetura, ou, mais amplamente, em modos localizados de vida, no patrimônio, nas memórias coletivas e nas comunhões afetivas), sendo preciso pô-los à parte das mercadorias normais, como camisas e sapatos. Talvez façamos isso porque somente conseguimos pensar a seu respeito como produtos e eventos que estão num plano mais elevado da criatividade e do sentido humano, diferente do plano das fábricas de produção de massa e do consumo de massa. No entanto, mesmo quando nos despimos de todos os resíduos de pensamento tendencioso (muitas vezes, com base em ideologias poderosas), ainda assim continuamos considerando como muito especiais esses produtos designados como "culturais". (HARVEY, 2005, p.221).

\section{Selva Iryapú: resistência de turismo na fronteira}

A insistência e persistência pelo seu lugar também é encontrada no Território Indígena Tekohá Iryapú (figura 8), comunidade Guarani em solo Argentino, os primeiros Guaranis chegaram nesta área há aproximadamente 120 anos, atualmente 100 famílias, de 8 a 10 parentelas totalizando aproximadamente 600 pessoas que sobrevivem basicamente do turismo, como a "cavalgada do índio solitário" que se trata de passeios a cavalo pela reserva, contemplando as paisagens naturais, conhecendo a história, a cultura da comunidade e de seu povo e do comércio de suas artesanias, encantadoras geografias portáteis. Sua arte e cultura representadas em artigos carregados de misticismo e criatividade (MARQUEZ, 2009).

\footnotetext{
${ }^{5}$ BENITEZ, Marina A.C. De plumas a estampados: una configuración de la imagen Maká. Dissertação (mestrado em estudos latino-americanos) Foz do Iguaçu: UNILA. 2016. $98 \mathrm{f}$
} 
Figura 8 - Portal de entrada Reserva Tekohá Iryapú em Puerto Iguazú.

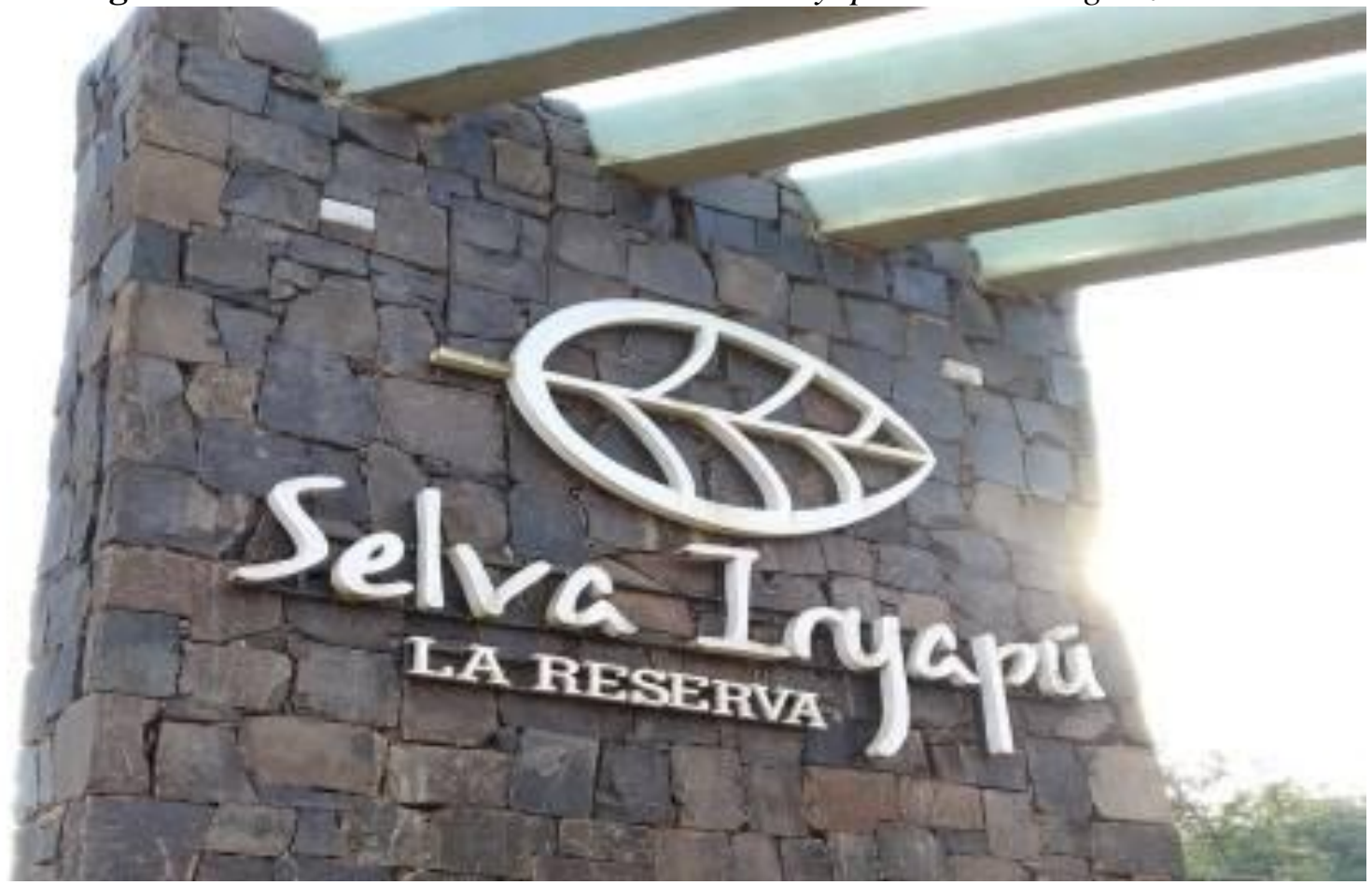

Fonte: PEREIRA, R.E. (2019). Trabalho de Campo.

A comunidade luta para conservar-se neste local valorizado economicamente, por onde passa o Rio Iguaçu, uma rota alternativa para as cataratas argentinas, onde a cultura indígena se sobressai aos apelos do capitalismo, que faz das ocas antes construídas de pau a pique e cobertas de palha, agora substituídas por casas de alvenaria. Tais moradias não possuem cercas, muros e nada do gênero, justamente para que vivam como uma grande família, mantendo vivas as tradições culturais indígenas. A comunidade recebeu algumas doações como a casa de reuniões, doada por uma ONG norte americana, uma escola para adultos, doação de uma "senhora de posses" que visitou o local, um projeto canadense que construiu um centro de capacitação para guias de turismo, tendo cursos oferecidos entre os anos de 2007 a 2010, o referido centro recebeu o nome de Escuela intercultural de Turismo de MBYAGUARANY - Instituto Clemencia Gonzalez-JACHUKAYVAPOTY. Algumas famílias recebem em suas casas energia elétrica, graças a placas solares doadas por ONG Suíça. Como pode ser percebido as culturas se entrelaçam em território guarani em terras argentinas, um complexo emaranhado cultural, uma teia de solidariedade e desejo pela emancipação econômica faz com que no Território Indígena Tekoa Iryapú a cultura tradicional guarani se misture as necessidades contemporâneas.

Outras vezes ainda devemos lembrar que os dois espaços só existem de fato graças às misturas entre si: o espaço liso não para de ser traduzido, 
EM

QUESTÃO

V.13 N. $04 \bullet 2020$

pág. 111-132

transvertido num espaço estriado; o espaço estriado é constantemente revertido, devolvido a um espaço liso. (DELEUZE e GUATTARI, 1997).

Na comunidade existe a Escuela Intercultural Bilingue AGUYJEVETE (figura 9) que atende 170 crianças e 40 estudantes secundários nos turnos matutino e vespertino, alfabetizados em guarani, espanhol e língua portuguesa, contando com três professores primários e dois secundários em classes multisseriadas, alguns Guaranis da comunidade frequentam a Universidade Nacional de Missiones. A liderança Guarani, o Cacique, é eleito pela comunidade, devendo estar na faixa etária compreendida entre 30-32 anos para candidatos a cacique e mantendo boa conduta permanece de 8 a 12 anos como liderança, caso contrário, a comunidade faz novas eleições e o substitui. O líder deve ser destemido e respeitado porque é sua responsabilidade a organização, a paz, o controle rigoroso da entrada de bebidas alcoólicas e a função de conselheiro das famílias.

Figura 9 - Escuela Intercultural Bilingue AGUYJEVETE.

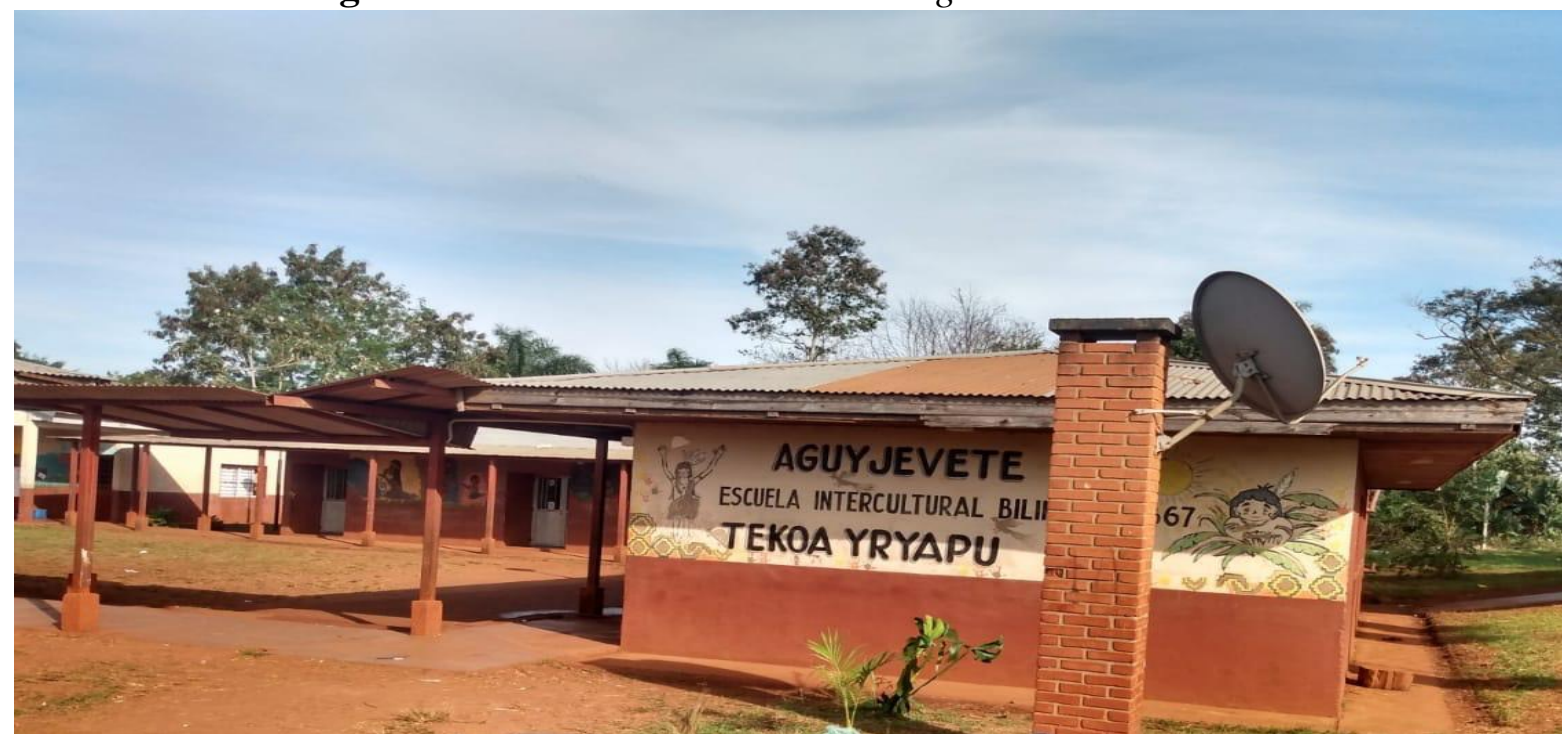

Fonte: PEREIRA, R.E. (2019). Trabalho de Campo.

A comunidade oferece aos visitantes passeios na trilha SENDERO YVYRA ROMI PALO ROSA onde apresenta seus contrastes da velha casa de reza feita de pau a pique e coberta por palhas e suas placas solares espalhadas as beiras do Sendero, simulam as caças e como funcionam suas armadilhas feitas com madeiras e cipós, que capturam desde pequenas aves até as temidas onças, e as casas de alvenaria doadas por norte americanos e europeus, uma riqueza cultural em cheque, porém lutando bravamente para ali se manter no território ocupado a séculos por seus ancestrais Guaranis. 
EM

Diante de uma história de ocupação do território, de resistência por se manter e de luta por seu lugar, o que se vê nas diferentes fronteiras é o mesmo curso, a mesma angústia e a afetividade em prova, a luta pelo que é seu, seu povo, seu território, sua cultura, sua moradia, enfim, seu lugar.

É logico que, na prática os espaços nos quais pensamos quase sempre "são" lugares, por serem dotados de significado e se conectarem a um "sentido de lugar", a um sense of place: o "lar", a igreja ou a escola que se frequenta ou frequentou, o bairro, o "torrão natal", a região... (SOUZA, 2015, p.118).

\section{Considerações finais}

Então, podemos entender que os locais e comunidade visitados se constituem como um novo território na linha da fronteira como decorrente de um processo de desterritorialização e reterritorialização, processo este que ocorre conjuntamente, e possui uma identidade própria:

O território não é apenas o conjunto dos sistemas naturais e de sistemas de coisas superpostas. O território tem que ser entendido como o território usado, não o território em si. O território usado é o chão mais a identidade. A identidade é o sentimento de pertencer àquilo que nos pertence. $\mathrm{O}$ território é o fundamento do trabalho, o lugar da residência, das trocas materiais e espirituais e do exercício da vida (SANTOS, 2002, p.10).

Segundo os moradores da "Linha Oito" "ninguém gosta de sem teto/sem terra", quando vão até a cidade de Mundo Novo, são vistos de forma pejorativa, e estão apenas "Lutando por um direito", não querem roubar ninguém, apenas querem o direito de pertencer, o que nos leva a crer que a construção do território demanda além da luta diária, a luta contra os preconceitos contra os que lutam, vivemos em um país onde acomodar-se a situações de exclusão é mais bem visto que a busca pela "igualdade de direitos", ou melhor dizendo, a amenização das desigualdades.

Conforme apontam Moreira e Medeiros (2013), a luta pela terra consiste na luta pela sobrevivência, recuperação da dignidade e cidadania, quando atores sociais saem da invisibilidade, se organizam e se manifestam para reivindicar junto ao Estado sua reterritorialização e reinserção social, deixando as marcas de sua luta na paisagem, que consiste na conquista da fração do território possibilitando a territorialização, a construção/reconstrução da vida, a reconstrução da dignidade, a afirmação do direito de 
existir, podendo ser lugar de mudança ou da recriação da sua cultura, sua autonomia, de sua capacidade de ascender política, social e economicamente. Com a efetivação da conquista afirmam sua existência e reafirmam o caráter complexo e também contraditório da fronteira.

Esta pesquisa oportunizou conhecer o ritmo de três diferentes comunidades que possuem uma mesma trajetória, uma realidade que ao mesmo tempo se distancia e se aproxima. Distancia-se geograficamente e se aproximam na resistência e luta pela manutenção da cultura, pela valorização de seu povo ou mesmo pela mais intensa necessidade de respeito ao direito básico da moradia digna. Nesse processo de conhecimento e reflexão é possível dialogar com os diferentes intelectuais que passam pela mesma elucubração em diferentes momentos históricos.

Apesar dos avanços e transformações ocorridos na sociedade no transcorrer dos tempos, alguns valores resistem em ser mantidos por seus povos e o principal deles é a manutenção de um povo reafirmando sua cultura em seu lugar, esse valor carregado de brio não permite que alguns apelos capitalistas transformem, embora alterem de uma maneira ou de outra, sua cultura de modo geral.

As comunidades fronteiriças estudadas trazem consigo riquezas e valores que o capitalismo com seu poderio jamais conseguiriam mensurar ou até mesmo comercializar e esses povos afortunados culturalmente sabem disso e não lançam mão dessa força que os mantêm em áreas ocupadas, herdadas ou mesmo sua de direito. Espaços que vão além de territórios, são seus lugares.

\section{Referências Bibliográficas}

ALBUQUERQUE, José Lindomar C. A dinâmica das fronteiras: os brasiguaios na fronteira entre o Brasil e o Paraguai.- São Paulo: Annablume, 2010.

ARRIAGADA, I. (1994) “Transformaciones del trabajo feminino urbano". Revista de la cepal 53, agosto.

cepal 77, agosto.

. (2002) “Cambios y desigualdade em las famílias latinoamericanas”. Revista de la

BAUMAN, Zygmunt, 1925 - Identidade: entrevista a Benedetto Vecchi / Zygunt Bauman; tradução: Carlos Alberto Medeiros. Rio de Janeiro, Zahar, 2005

BENITEZ, Marina A.C. De plumas a estampados: una configuración de la imagen Maká. Dissertação (mestrado em estudos latino-americanos) Foz do Iguaçu: UNILA. 2016. $98 \mathrm{f}$ 
EM

QUESTÃO

V.13 N. $04 \bullet 2020$

pág. 111-132

BORDIEU, Pierre. O poder simbólico. Tradução de Fernando Tomaz. Rio de Janeiro: Bertarnd do Brasil, 1998a.

CAMPOS, Heleniza Ávila. Cidades Em Fronteira: Discussão Sobre Seus Múltiplos Significados. $1^{\circ}$ Colóquio Internacional de História Cultural da Cidade, Porto Alegre, p.393406, 2015.2 Disponível em: <http://www.ufrgs.br/gthistoriaculturalrs/27CDHelenizaAvilaCampos.pdf>. Acesso em: 16 jul. 2019.

CARVALHO, Paulo Ernani Ramalho; ministério da agricultura pecuária e abastecimento. 57: timbó. 1 ed. Colombo, 2002. 7 p. Disponível em: <https://www.infoteca.cnptia.embrapa.br/bitstream/doc/304554/1/CT0057.pdf>. Acesso em: 18 jul. 2019

CASTEL, Robert (1995). Les Metamorphoses de la question sociale. Une chronique du salariat. Paris, Fayard in Desigualdade e questão social. 2004. Ed. Educ. São Paulo.

DELEUZE, Gilles; GUATTARI, Félix. Mil platôs: capitalismo e esquizofrenia. V.5. Ed. 34, São Paulo, 1997.

ELIAS, Norbert, 1897-1990 E41e. Os estabelecidos e os outsiders: sociologia das relações de poder a partir de uma pequena comunidade. Rio de Janeiro: Jorge Zahar Ed., 2000.

FERRARI, Maristela. Zona de fronteira, ciudades gêmeas e interações transfronteiriças no contexto do MERCOSUL. Revista Transporte y Territorio, Buenos Aires, v. 9, n. 0, p.89104, dez. 2013. Disponível em: <http://revistascientificas.filo.uba.ar/index.php/rtt/article/view/305/283>. Acesso em: 22 jul. 2019.

GOMES, Horieste. A produção do espaço geográfico no capitalismo- $2^{\circ}$ ed. São Paulo: Contexto, 1991- ( Coleção repensando a geografia)

HAESBAERT, Rogério. Desterritorialização: entre as redes e os aglomerados de exclusão. In: CASTRO, Iná E.; GOMES, Paulo César da C. e CORRÊA, Roberto Lobato (Orgs). Geografia: conceitos e temas. Rio de Janeiro: Bertrand Brasil, 1995.

EDUFF, 1997.

Des-Territorialização e Identidade: a rede "gaúcha" no nordeste. Rio de Janeiro,

HARVEY, David. A produção capitalista do espaço- São Paulo: Annablume, 2005.

.17 contradições do capitalismo- 1 ed. São Paulo: Boitempo, 2016.

HOLZER, W. Uma discussão fenomenológica sobre os conceitos de paisagem e lugar, território e meio ambiente. Território. Rio de Janeiro, n. 3, jul./dez. 1997.

IANNI, Otávio. A metáfora da viagem. In: Revista de Cultura Vozes, Petrópolis, ano 90,v.90, n.2, mar./abr. 1996. 
MARQUEZ, Renata Moreira. Geografias portáteis: arte e conhecimento espacial. Tese de Doutorado. Belo Horizonte: PPGG - Instituto de Geociências - UFMG, 2009. Disponível em: http://www.geografiaportatil.org/files/geografias-portateis-p.pdf, acesso em 05 de agosto de 2019.

MARTINS, Jose de Souza. A sociedade vista do abismo. 2003, 2ed. Ed. Vozes. Petrópolis.

O tempo da fronteira. Retorno à controvérsia sobre o tempo histórico da frente de expansão e da frente pioneira. Tempo Social; Rev. Sociol. USP, S. Paulo, 8(1): 25-70, maio de 1996.

MOREIRA, V.S.; MEDEIROS,R.M.V. Reflexões sobre o território e a territorialidade para compreender o despertar de um movimento social. In SAQUET, M.A.(Org.) Estudos territoriais na ciência geográfica. São Paulo: outras Expressões, 2013.

NOGUEIRA, Bárbara Freitas Ribeiro; CLEMENTE, Claudelir Correa. Etnografia da tríplice fronteira: primeiras aproximações. Horizonte Cientifico, Uberlândia, v. 5, n. 2, p.1-21, dez. 2011. Disponível

em: <http://www.seer.ufu.br/index.php/horizontecientifico/article/view/12206>. Acesso em: 16 jul. 2019.

POLON, Luana Caroline Künast. Brasil - Paraguai: considerações sobre a "fronteira do consumo". Tempo da Ciência, Toledo, v. 22, n. 44, p.71-77, 2015. Disponível em: <http://erevista.unioeste.br/index.php/tempodaciencia/article/view/12933/8935>. Acesso em: 16 jul. 2019.

POUTIGNAT, Philippe; STREIFF_FERNART, Jocelyne. Teorias da etnicidade. Seguido de Grupos étnicos e suas fronteiras de Fredrik Barth. São Paulo: Editora da UNESP, 2011.

SANTOS, M. Território e Dinheiro. In: Programa de Pós-Graduação em Geografia da UFF. Território, Territórios. Niterói: PPGEO-UFF/AGB-Niterói, RJ. 2002.

SAQUET, Marcos Aurélio. Abordagens e concepções sobre território São Paulo: Outras Expressões, 2015.

. Os tempos e os territórios da colonização italiana. O desenvolvimento econômico da Colônia Silveira Martins (RS). Porto Alegre: EST Edições 2003 (2001).

SOUZA, Marcelo Lopes. Os Conceitos Fundamentais da Pesquisa Sócio espacial. Bertrand Brasil. Rio de Janeiro. 2015

VAllA, V.V.; STOTZ, E.N.; ALGEBAILE, E.B. Para Compreender a Pobreza no Brasil. Rio de Janeiro: Contraponto, 2005.

VIEIRA, A, B. Mapeamento da exclusão social em cidades médias: interfaces da Geografia Econômica com a Geografia Política.2009. 208f. Tese (Doutorado em Geografia) - Faculdade de Ciências e Tecnologias, Universidade Estadual Paulista, Presidente Prudente. 
Artigo recebido em 10-09-2020

Artigo aceito para publicação em 20-11-2020 